\title{
GRUPO DE SUPORTE À FAMÍLIA DA PESSOA COM DOENÇA MENTAL GRAVE: ESPAÇO DE PARTILHA NA ADVERSIDADE
}

\author{
GROUP OF SUPPORT TO THE FAMILY OF RELATIVES OF PATIENTS WITH \\ SEVERE MENTAL ILLNESS: SPACE OF SHARING IN ADVERSITY
}

Idalina Delfina Gomes', Maria dos Anjos Pereira Lopes ${ }^{2}$, Maria do Céu Pires Delgado
Monteiro ${ }^{3}$, Marta Lima Basto ${ }^{4}$, Célia Simão de Oliveira ${ }^{5}$, Maria Antónia Rebelo Botelho ${ }^{6}$,
Maria Paula Silveira Nunes ${ }^{7}$, Eduardo Jorge Delgado Catarino ${ }^{8}$, Adriana Henriques

'Autor correspondente: idgomes@esel.pt

1, 2, 4, 5, 6, 9 Doutora em enfermagem. Professora na Escola Superior de Enfermagem de Lisboa e Investigadora na Unidade de Investigação e Desenvolvimento em Enfermagem (UI\&DE). Lisboa. Portugal. idgomes@esel.pt; maveiga@esel.pt; mlimabasto@esel.pt; coliveira@esel.pt; rbotelho@esel.pt; ahenriques@esel.pt. ${ }^{3}$ Mestre em Enfermagem com a especialização em Enfermagem de Saúde Mental e Psiquiátrica. Investigadora da UI\&DE e Enfermeira na Clínica Psiquiátrica V, do Centro Hospitalar Psiquiátrico de Lisboa (CHPL). Lisboa. Portugal. ceumonteiro@chpl.min-saude.pt. ${ }^{7}$ Psiquiatra Assistente Graduada na Clínica Psiquiátrica V, do CHPL. Lisboa. Portugal. paulanunes@chpl.min-saude.pt. ${ }^{8}$ Enfermeiro Chefe e Especialista em Enfermagem de Saúde Mental da Clínica Psiquiátrica V, do CHPL. Lisboa. Portugal. jorgecatarino@chpl.min-saude.pt.

RESUMEN I Objetivo: compreender as condições e contexto que levam os familiares de doentes com doença mental grave a participarem no grupo de suporte num Hospital Psiquiátrico. Método: Estudo qualitativo, segundo Grounded Theory. Participantesfamiliares de doentes que frequentam o Hospital de dia. Procedimentos: sessões de grupo áudiogravadas, entrevistas a membros da equipa de saúde, questionário aos familiares, notas de campo de incidentes críticos. Resultados: as condições e contexto que fazem com que os familiares se reúnam no grupo de suporte é a aliança na adversidade devido ao estigma da doença mental que devasta a vida das pessoas doentes e suas famílias em todas as dimensões do seu quotidiano pelo que o grupo de suporte constitui um porto de abrigo. Conclusão: no grupo os familiares partilham aprendizagens, estratégias e aprendem a gerir o quotidiano incerto. Esta é uma estratégia relevante para melhorar o cuidado profissional que é dado as pessoas com doença mental grave e seus familiares em casa.

\begin{abstract}
Objective: to understand the conditions and context that lead the relatives of patients with severe mental illness to participate in the support group in a Psychiatric Hospital. Method: Qualitative study, according to Grounded Theory. Participants family members of patients attending day hospital. Procedures: audio-taped group meetings, interviews with members of the health team, family members' questionnaire, critical incident field notes. Results: The conditions and context that make the family members in the support group is the alliance in adversity due to the stigma of mental illness that devastates the lives of sick people and their families in all dimensions of their daily lives, so the group is a shelter. Conclusion: in the group the family members share learning, strategies and learn to manage uncertainty in everyday life. This is a relevant strategy to improve the professional care given to the people with severe mental illness and their families at home.
\end{abstract}

Keywords: Caregivers; Mental Disorders; Support group

Palavras-chave: Cuidador familiar; doença mental grave; grupo de suporte 


\section{INTRODUÇÃO}

Os avanços obtidos na psiquiatria no tratamento de pessoas com doença mental possibilitaram, nos últimos cinquenta anos, a diminuição do número e duração dos internamentos, aproximando a pessoa doente da comunidade e da sua família. Esta tem vindo a adquirir uma maior importância e a ser considerada como um recurso relevante na reabilitação de pessoas com doença mental grave (DMG), dada a escassez ou mesmo a ausência de outras estruturas de apoio (Gonçalves-Pereira et al., 2012).

A família é um parceiro fundamental no acompanhamento e apoio dos seus membros quando um deles tem uma DMG. Esta é definida como uma situação que pelas suas características e evolução do quadro clínico, afecta de forma prolongada e contínua a funcionalidade da pessoa e família (Kuipers, Leff, \& Lam, 2006). A transição de saúde-doença vivida pela família pode gerar disfuncionamento e vulnerabilidade acrescida (Meleis, 2010). A família precisa de perceber antecipadamente as dificuldades com que se vai deparar para enfrentar o diagnóstico de uma DMG num membro da sua família, para o que necessita de ajuda profissional. Esta transição será sempre desgastante e morosa, quer pelo estigma que the está ligada, quer pela difícil e complexa gestão dos comportamentos da pessoa doente no quotidiano.

A vida da pessoa com DMG é de elevado sofrimento bem como o da família que altera toda a sua dinâmica de forma nem sempre salutar. É por isso necessário encontrar estratégias de intervenção que permitam, desde o início, o acompanhamento, apoio e orientação destas famílias tendo-se revelado úteis as intervenções psicossociais, nomeadamente através dos grupos de suporte (Gonçalves-Pereira et al., 2012; Torres, Lima, \& Guerra 2014).

O diagnóstico de uma doença mental grave, no seio de uma família, gera uma situação de vulnerabilidade acrescida, pois há fatores que não controla, sejam estes de origem endógena, social, ou ambiental. Os familiares dos doentes com DMG vivem no seu quotidiano íntimo com um familiar cujos comportamentos não compreendem, que fogem ao seu controlo e temem por si e pelo próprio doente.
Assim a família está exposta a viver num ambiente de stresse continuado pelas reações imprevisíveis que são desencadeadas por fatores que não entende de que é exemplo a falta de cooperação no tratamento. Os familiares e amigos são evitados para se furtar dar corpo a um diagnóstico negado. Embora a esperança de melhoria seja sempre acalentada os sucessivos retrocessos demoram a dar sinais geradores de algum otimismo (Levy-Frank, Hasson-Ohayon, Kravetz, \& Roe, 2011).

De acordo com a Comissão Nacional para a Reestruturação dos Serviços de Saúde Mental (20072016), qualquer que seja a forma de intervenção dos profissionais, a relação com os familiares é uma questão central. Esta requer uma boa interrelação entre utentes, familiares e profissionais, os quais têm que ter uma atitude sistemática de atenção, compreensão, disponibilidade, postura capaz de estimular a comunicação e consolidar uma aliança empática, de confiança, de respeito mútuo, de esperança e articulação de metas entre profissionais, pessoa doente e familiar cuidador. $O$ objetivo é promover um clima em grupo através do qual os familiares se possam apoiar mutuamente. A instilação de esperança é um ingrediente necessário na psicoterapia. É importante que os terapeutas reforcem diretamente $\circ$ potencial da abordagem grupal e enfatizem resultados positivos que a participação nos grupos de suporte confirmam (Figueiredo \& Charepe, 2010).

Muitas outras intervenções terapêuticas são por certo utilizadas quando os enfermeiros e restantes elementos da equipa procuram ajudar os doentes a lidar com a transição suscitada por uma DMG. Estas situações exigem uma intervenção de cuidados de saúde e em particular de Enfermagem pois, segundo Meleis (2010), tais transições se não apoiadas, podem gerar disfuncionamentos que conduzirão a novas doenças. O poder das famílias não é o poder dos técnicos, tendo mais impacto. $O$ poder das associações de famílias é ímpar e insubstituível. Os objetivos familiares e institucionais devem ser coincidentes e orientados na perspetiva do que é melhor para a pessoa doente.

De acordo com o plano de reestruturação dos serviços de Saúde Mental (2007-2016), os familiares de pessoas com doença mental devem ser 
considerados essenciais na prestação de cuidados de saúde mental. Isto porque se considera que a presença dos familiares, no tratamento, proporciona conforto e tranquilidade a ambos, ajudando a manter a pessoa doente no seio da família.

Contudo, na crescente responsabilização das famílias de pessoas com DMG assiste-se a um panorama em que as mesmas carecem de informações básicas ou treino de competências que lhes possibilitem serem capazes de cuidar do familiar com DMG. Sem estas competências o cuidado transforma-se numa sobrecarga que as mesmas podem não ser capazes de gerir adequadamente, acabando por comprometer a sua saúde (Nirmala, Vranda, \& Reddy, 2011).

Se muitas das dificuldades destas famílias são conhecidas, a dinâmica de sobrevivência adotada e as aprendizagens que decorrem do seu saber experiencial continuam enigmáticas. Além disso, se existe investigação sobre intervenções psicoeducativas, o mesmo não acontece relativamente a intervenções de grupos de suporte com um funcionamento menos formal, mas ajustado às possibilidades das organizações de saúde. Importa por isso estimular, dar visibilidade e suporte às atividades que realizam para que estas se efetuem de um modo mais organizado, sistemático e efetivo (Grácio, Gonçalves-Pereira, \& Leff, 2016).

Assim, foi desenvolvido num Hospital Psiquiátrico de Lisboa (CHPL) um grupo de suporte com uma metodologia de trabalho, com duas sessões por mês, focalizada no apoio e orientação dos familiares de pessoas com DMG. A evidência em outras realidades semelhantes sugere a efetividade deste tipo de intervenção para os familiares das pessoas doentes (Grácio, Gonçalves-Pereira, \& Leff, 2015; McFarlane, 2016).

Este artigo tem como objetivo permitir compreender quais as condições e o contexto que levam os familiares dos doentes com DMG a participarem no grupo de suporte do CHPL.

\section{METODOLOGIA}

Estudo qualitativo, seguindo a grounded theory de Strauss e Corbin (1998). Os participantes foram os familiares de doentes com DMG (24), que frequentavam o grupo de suporte do Hospital Psiquiátrico de Lisboa. Optámos por esta abordagem pois era nossa intenção compreender os modos de pensar, sentir e agir dos cuidadores familiares de pessoas doentes com DMG perante as dificuldades vividas no quotidiano. Em particular, pretendíamos compreender a conjuntura que leva os familiares dos doentes com DMG a participarem no grupo de suporte do CHPL, o que implica responder às perguntas: $O$ quê? Como? Onde? Porquê? (Strauss e Corbin, 1998).

\section{Instrumentos de colheita de dados}

Os dados foram colhidos entre Março de 2013 e Março 2015 através da observação não participante de 12 sessões do grupo de suporte, documentadas por audiogravação, notas de campo relativas a cada uma das sessões de grupo incluindo os períodos de convívio e questionários com perguntas abertas (24) a cada participante no grupo. Para identificar os participantes foram utilizados letras e números. Na codificação das sessões áudio gravadas usouse a sigla $R G$, com a respetiva enumeração e na codificação dos questionários usou-se a sigla Rl, com a respetiva enumeração. Foram também realizadas 2 entrevistas em profundidade, áudio-gravadas, ao facilitador do grupo e 2 entrevistas informais à psicóloga por ser o membro da equipa de saúde que manteve mais regularidade de presença, com o objetivo de clarificar aspetos relativos a dinâmica do grupo. A análise de todos estes dados foi realizada pelo método das comparações constantes.

\section{Contexto do estudo}

O grupo de suporte decorre no CHPL desde 2009, onde teve início no Hospital de Dia. Em 2014 o grupo mudou para o serviço de Clínica Psiquiátrica $V$ - não tendo ocorrido alterações relevantes na filosofia de orientação do grupo, mantendo-se ainda em funcionamento atualmente. $O$ grupo de suporte reúne duas vezes por mês, das $13 \mathrm{~h} 30 \mathrm{~m}$ às $15 \mathrm{~h} 30 \mathrm{~m}$. 
A equipa de saúde inclui o enfermeiro especialista de saúde mental, que coordena a sessão, um psicólogo, e de forma mais irregular um psiquiatra e uma assistente social. Toda a equipa de saúde mantem nas reuniões uma posição discreta e com intervenção muito pontual. A duração de permanência dos familiares no grupo é ilimitada. Houve uma frequência média de 7 familiares por sessão.

\section{Princípios éticos}

O projeto foi aprovado pela Comissão de Ética da instituição onde decorre esta intervenção. Todos os familiares receberam informação sobre o estudo e sobre os seus direitos. Deram consentimento informado para participar, aceitando, por escrito, a presença de um investigador nas sessões do grupo bem como a gravação áudio.

A equipa de saúde e a Administração do CHPL autorizaram a identificação do serviço e a instituição onde decorre o estudo.

\section{Análise dos dados}

Recorreu-se aos princípios da Grounded theory (Strauss \& Corbin, 1998), tendo a análise dos dados sido caracterizada pela comparação constante das semelhanças e diferenças do que se observou e do que foi dito pelos participantes, ou seja, entre os códigos e entre as categorias, permitindo aos investigadores realizar $\circ$ que se denomina por amostragem teórica. Está é conduzida pela análise dos dados, orientando o investigador no processo de seleção da amostra e recolha de dados pertinentes para elaborar e refinar as categorias.

As questões orientadoras para a colheita e análise de dados foram as seguintes:

- Quais os significados que os familiares dos doentes com DMG atribuem ao processo de estar no grupo?

- O que é quê os faz estar no grupo? E como expressam isso?

- Porque é que estão no grupo? O que enfatizam no grupo?

O processo de codificação contemplou três níveis: codificação aberta, axial e selectiva (Strauss \& Corbin, 1998).

A codificação aberta é considerada o primeiro nível de codificação e é realizada à medida que o investigador vai colhendo os dados. Consiste em codificar cada frase, utilizando tantos códigos quantos os necessários, para assegurar uma análise minuciosa da informação transmitida. $O$ investigador vai procurando fazer emergir os conceitos implícitos nos dados para construir as categorias, as suas propriedades e dimensões, tal como se ilustra na figura seguinte.

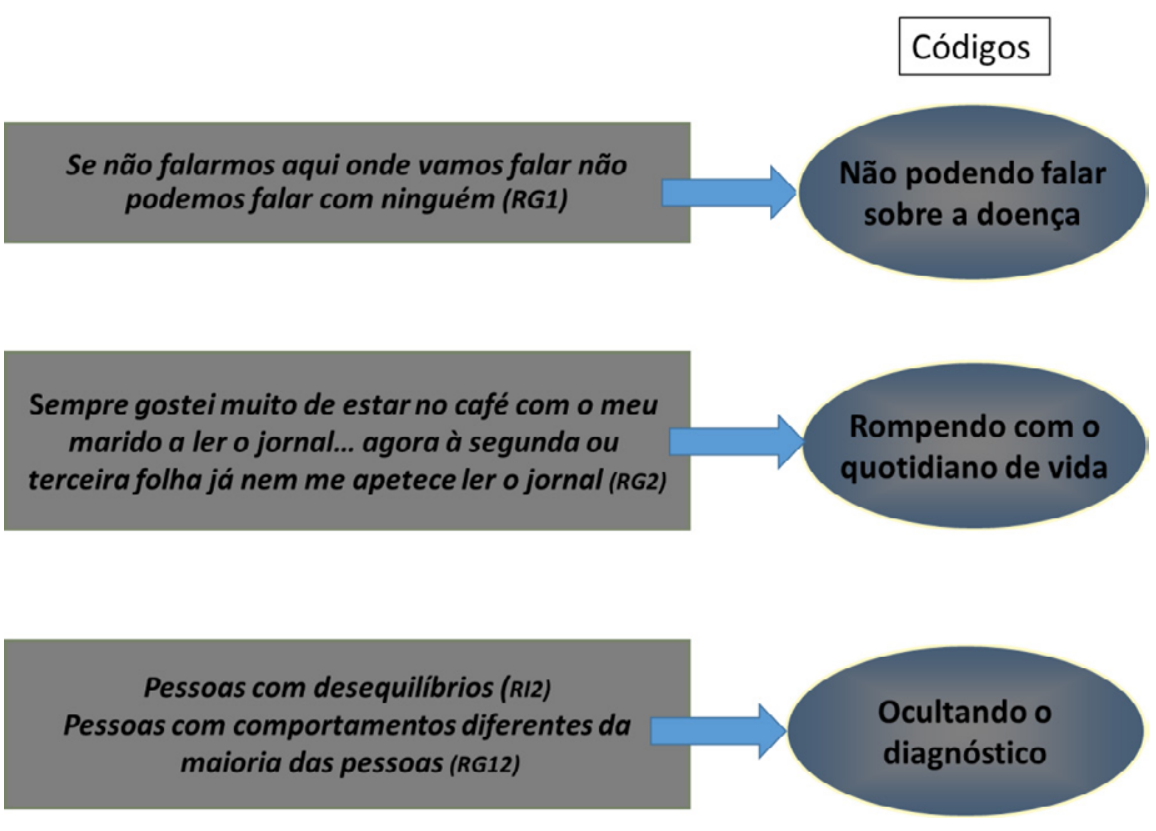

Figura 1 - Diagrama da codificação aberta (Fonte: os autores) 
A codificação axial é o segundo nível de codificação e consiste em identificar os códigos substantivos, assim designados por conterem a substância dos dados, os quais são constantemente comparados e agrupados, de acordo com uma orientação lógica, visando identificar as categorias e subcategorias e relacionálas, com base nas suas propriedades e dimensões. Assim, identificámos as categorias e subcategorias, agrupámo-las e categorizámo-las em termos cada vez mais abstratos, visando formular explicações sobre ○ fenómeno com base nas respostas às perguntas: $O$ que é que faz os familiares irem para - grupo de suporte? (O Quê); Face a essa conjuntura, como fazem os familiares? (Como?); Onde o Fazem? (Onde?); Porque é que o fazem? (Porquê?), conforme se ilustra na figura seguinte.

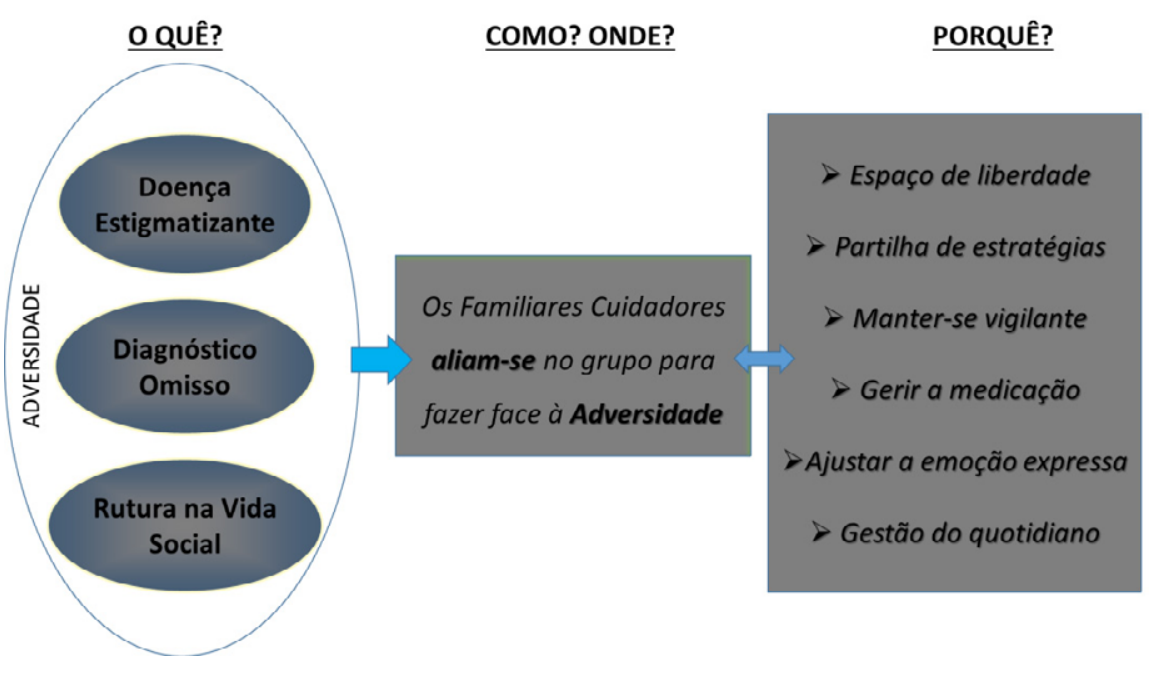

Figura 2 - Diagrama de uma etapa da codificação axial (Fonte: os autores)

A codificação seletiva é o terceiro nível de codificação e consiste na integração de categorias para construir as estruturas teóricas, ou seja, a categoria central à volta do qual se reagruparão e integrarão as outras categorias (Strauss \& Corbin, 1998). Assim, a codificação e a utilização de memos analíticos (descrições do investigador à medida que decorre a análise dos dados e revelam pensamentos, interpretações que encaminham para novas questões e direções na colheita de dados) permitiu gerir os conceitos, integrar as categorias, visando a saturação de cada uma delas e o emergir da categoria central que surgiu como aliança na adversidade, possibilitando a elaboração da estrutura teórica explicativa do processo em estudo, conforme se explicita no capítulo dos resultados.

A validade dos achados foi efetuada por três elementos da equipa de saúde, mas foi sobretudo mobilizada a reflexividade dos investigadores sobre os dados, sendo a escrita de memos uma estratégia metodológica usada e muito útil (De La Cuesta \& Carmen, 2015).
Outra estratégia utilizada foi confrontar os achados encontrados com os familiares participantes que se reviram nos mesmos. Como refere Leininger (2005), um dos critérios de validade dos estudos qualitativos é o significado em contexto. Este critério centra-se na contextualização das ideias e das experiências inerentes a uma situação ou no meio ambiente total, dados que se tornam compreensíveis dentro de contextos holísticos ou têm significados dos referentes especiais para os participantes.

\section{RESULTADOS}

Os achados mostraram que a adesão e participação no grupo deriva do grande sofrimento que 0 confronto com a DMG provoca nas famílias, que perante essa adversidade se aliam em volta da dinâmica do grupo para prosseguir com o seu quotidiano de vida. O grupo de suporte tornase um verdadeiro porto de abrigo (Gomes, et al., 2017). Na figura 3 representa-se a estrutura teórica explicativa deste processo. 


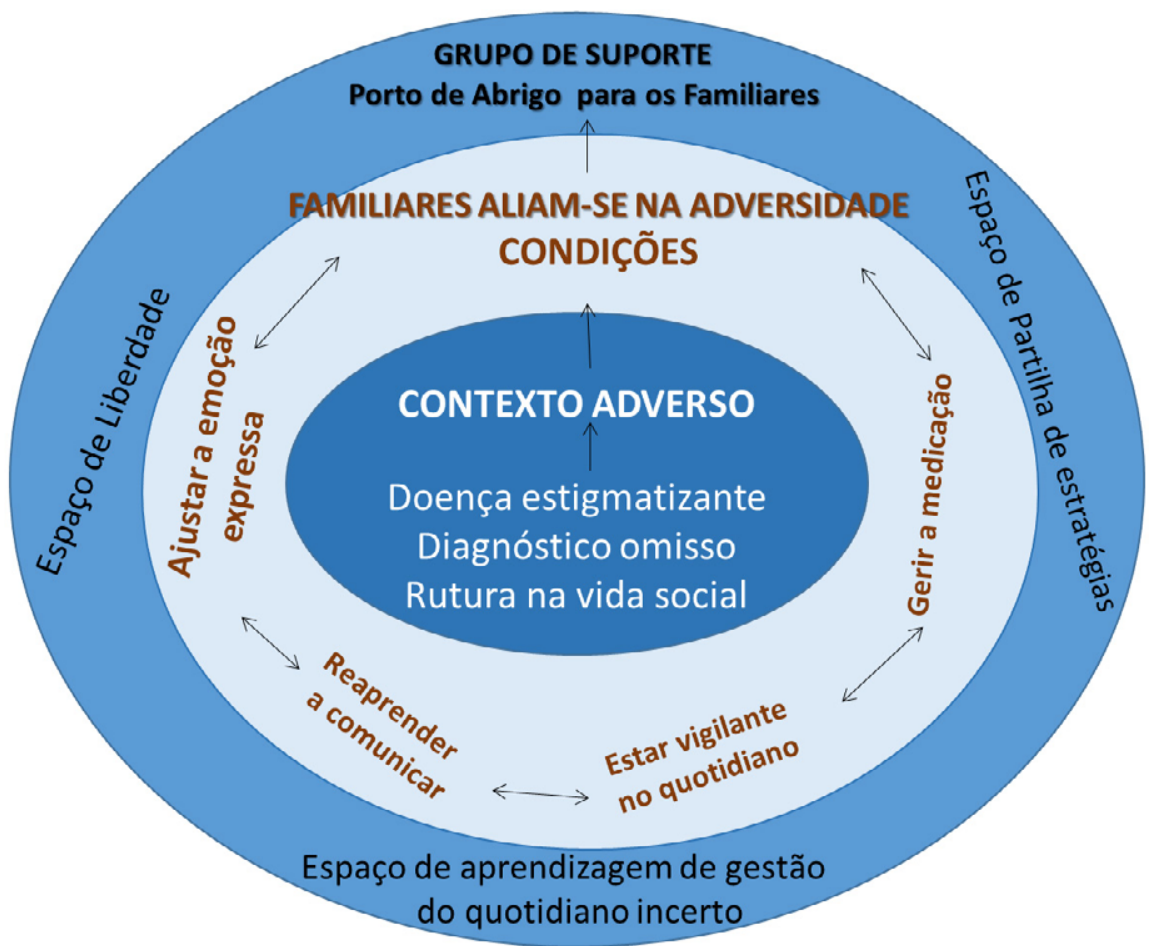

Figura 3 - Diagrama da estrutura teórica explicativa das condições e contexto do grupo de suporte a familiares com DMG (Fonte: os autores)

A doença transforma e torna quase irreconhecível a pessoa doente, deteriorando a vida familiar pela fuga ao diálogo no seio das famílias, bem como pela fuga dos contatos sociais, podendo mesmo provocar rutura social no seio familiar derivado do estigma que ainda paira sobre a doença mental.

O estigma da doença mental leva a que o diagnóstico seja ocultado e omitido pela família, não sendo nomeado mesmo quando o internamento já ocorreu. Os eufemismos usados pessoas com desequilíbrio, pessoas com comportamentos diferentes da maioria das pessoas (RG3), mostram a negação e dificuldade de aceitação da doença. $O$ ambiente de suspeição e encobrimento perante familiares e amigos acentua $\circ$ isolamento e sofrimento.

A falta de compreensão da doença mental leva assim à fuga dos contatos sociais, provocando rutura social na vida da família, principalmente do cuidador familiar pelo absorvente papel no quotidiano, chegando mesmo a descurar o cuidado de si e esquecer outros papéis familiares. O excerto a seguir mostra como a doença mudou os hábitos de lazer de um cuidador familiar ...sempre gostei muito de estar no café com o meu marido a ler o jornal...agora à segunda ou terceira folha já nem me apetece ler o jornal (RG2).
O cuidador familiar pelo continuado e absorvente papel que the é exigido no quotidiano tem níveis de elevado sofrimento e desgaste face ao leque de problemas e sentimentos com que tem de lidar. Estes processos tanto podem gerar transformações positivas, como desencadear recuo e desgaste no desenvolvimento do cuidador, consoante a mobilização de recursos internos e externos disponíveis.

O risco de exaustão do cuidador familiar existe, pois há dias muito difíceis de gerir por não saber o que fazer, assim metaforicamente afirmado: por vezes os dias apresentam-se muito escuros (RG5). O grupo é um recurso percebido como muito positivo por todos os familiares. É um espaço de partilha, acolhimento para os familiares de pessoas com DMG. Ao poderem escutar casos idênticos aos seus constatam que não se encontram sozinhos. Ocorrem fenómenos no contexto do grupo de suporte que têm um efeito de identificação ao comprovar as semelhanças de comportamentos que existem noutras famílias. Estas sentem-se ajudadas, pois embora as pessoas sejam todas diferentes, há muitos comportamentos que são comuns pela doença subjacente. Dizia uma familiar: ao frequentar este grupo vejo que não estou tão sozinha, há muita gente a viver estes momentos igualmente de angústia (RG10). Estar 
acompanhado no processo de sofrimento minimiza a solidão, conforta e diminui o sentimento de exclusão.

O grupo de suporte também se assume como local de âmbito pedagógico, pois têm contacto com outros familiares mais experientes que já descobriram muitas soluções. Assim estes funcionam como modelo para os que entram de novo, para quem tudo é novo, desconhecido e assustador. Um cuidador familiar referia $\circ$ seu desconhecimento para conseguir gerir a situação que vivenciou como algo perturbador e estranho na sua vida, assim dizia: quando se vive o problema tão intensamente e estamos muito envolvidos, fazemos de tudo um bicho-de-sete-cabeças (RG10).

O grupo de suporte para um familiar que começa a frequentá-lo tem fundamentalmente uma função educativa $\grave{A}$ medida que este se integra tornase local de partilha, onde têm a possibilidade de falar e de ser ouvido, sem ser julgado, pois todos vivem problemas idênticos. A este propósito um familiar referia: Também já tive esta e aquela dúvida, é curioso haver mesmo assim tanta semelhança (RG 12). É no diálogo e na partilha de experiências que os familiares no contato próximo uns com os outros conseguem tomar conhecimento de estratégias e formas de comunicação para lidar com o seu familiar. $O$ grupo de suporte também ajuda a perspetivar soluções, pois permite pensar que existem diferente maneiras de agir e ponderar outras soluções, sobretudo quando se sentem menos otimistas. $O$ fato de ver pessoas com esperança faz com que se sintam mais confortados.

Neste espaço reaprendem também a comunicar. $O$ medir as palavras e usá-las no momento e forma certa, requerem uma aprendizagem contínua, geradora de desgaste no dia-a-dia. $O$ receio de provocar crises no seu familiar doente, é algo muito sublinhado, embora seja referido de forma indelével nos discursos, podendo significar gravidade e fracasso na situação que até o mencionar se torna penoso. Assim, o aprender a comunicar pode ajudar a ter alguma estabilidade nos comportamentos. $O$ familiar cuidador aprende sobretudo através da tomada de consciência dos erros que cometeu, sendo todavia um processo de aprendizagem muito lento e difícil.
A adesão à medicação é a grande esperança do familiar para a estabilidade da doença acontecer. Por outro lado, a medicação é repudiada pela pessoa doente, pois sente que altera a sua essência. Neste contexto, o familiar vigia atentamente a sua ingestão, ajuda a pessoa doente a não esquecer de a tomar. A medicação é um recurso que exige esforço ao familiar pois tem de se empenhar para que o doente não a pare e seja tomada regularmente.

Para que a medicação faça o seu efeito a exclusão do álcool tem de ser respeitada, sendo esta uma questão por vezes mal compreendida e aceite pela pessoa doente. Os amigos muitas vezes não sabem do efeito do álcool na medicação e não contribuem para evitar o respetivo consumo, motivo pelo qual o familiar cuidador procura o seu afastamento do familiar doente.

A medicação altera a pessoa doente e provoca na família uma relação de amor-ódio relativamente ao tratamento. Esta relação deriva do duplo papel que a medicação tem em si mesma. Se por um lado ajuda a estabilizar os sinais e sintomas da doença, por outro lado também tem efeitos negativos pois altera o normal comportamento da pessoa, tonandoos por vezes apáticos.

Das maiores dificuldades que o cuidador familiar vive é saber qual a justa medida do seu agir. A vigilância a manifestar, o reparo a fazer, a pergunta a colocar, ter a perceção do momento mais adequado para falar, saber quando o silêncio inquietante deve ser interrompido, a dúvida permanente sobre o melhor comportamento a adotar, fazem com que o quotidiano seja de constante hesitação e indecisão. O familiar cuidador tem dificuldade de saber se foi invasivo, se pode questionar, qual o modo e momento próprio para o fazer, se deve aguentar a dúvida ou esperar que a resposta apareça com naturalidade. Estas são situações que fazem com que o dia-a-dia seja sempre perturbador, altamente stressante pelo viver e agir em sobressalto. A insegurança é assim expressa: depois de cada atitude que tomamos, ficamos sempre com uma espécie de remorso, de culpa, ou porque exigimos demais ou de menos (RG5).

A inter-relação familiar cuidador pessoa doente tem a particularidade de ser um processo de mudança a dois, na medida em que ambos mudam: o familiar 
e a pessoa com doença mental grave, articulamse e influenciam-se mutuamente no processo de gestão da doença. Um familiar cuidador referia: Levei muitos anos para mudar um bocadinho, ... ele agora também está a mudar ou eu automaticamente meto-o a mudar, estamos a mudar os dois... (RG.8).

Perante estas condições contextuais adversas os familiares dos doentes com DMG ao participarem no grupo de suporte aliam-se para fazer face às condições de adversidade. Neste grupo encontram um espaço de liberdade e partilha de estratégias que vão descobrindo ao mesmo tempo que desenvolvem o seu processo de gestão emocional, onde a resiliência é imperiosa ser mobilizada e cultivada, pois é fundamental ajustar a emoção expressa. $O$ grupo de suporte revela-se assim como um efetivo porto de abrigo, pois ali são todos iguais, competentes/ incompetentes na vivência deste grave problema, em que todos têm momentos de ânimo e desânimo, bem como momentos de sucesso e insucesso.

\section{DISCUSSÃo}

As hesitações e dificuldades relativas ao enfrentar - diagnóstico da DMG e ao estigma que a acompanha, aliada à complexidade dos ajustes da medicação mais adequada e ao esforço na adesão à terapêutica ao longo do tempo para estabilizar a doença, são alguns dos elementos de indescritível dificuldade dentro da gestão desta doença crónica. $O$ desgaste físico e psicológico é inevitável, sendo a sua minimização uma conquista diariamente construída através da gestão da sintomatologia da DMG.

O quotidiano é o reflexo de uma boa ou inadequada gestão da vida diária, pois é nele que se reflete a importância da vida. O quotidiano é o que mais próximo se encontra do interior das pessoas, é o que é mais invisível, escondido, dissimulado e, no entanto, tão importante na perceção do verdadeiro sentido da existência (Crespo, 2006). A família, pelo seu papel tradicional, tem uma função preponderante no acompanhamento e apoio dos seus membros na segurança dos mesmos, assumindo a responsabilidade pela garantia da continuidade de cuidado do processo terapêutico do seu familiar. Todavia esta não pode ser deixada sozinha neste processo de cuidados e intricada gestão de sintomas que caracterizam a DMG, sendo os grupos de suporte uma simples parcela da ajuda a que as famílias têm direito. Os familiares conseguem ir encontrando estratégias para gerir a incerteza do seu dia-a-dia muitas vezes por tentativa e erro, mas tal situação configura abandono do sistema de saúde, não podendo, nem devendo ser da sua exclusiva responsabilidade (Grácio, GonçalvesPereira, \& Leff, 2016).

O grupo de suporte, com uma intervenção profissional especializada, exerce um "efeito terapêutico" nos seus membros, como referem Torres, Lima \& Guerra (2014), uma vez que a sua formação é espontânea, ocorre entre pessoas que têm em comum um familiar com DMG e têm condições para se ajudarem mutuamente. $\bigcirc$ grupo de suporte é uma estratégia sinergética que intervém a nível educativo e apoio emocional, pois permite ao cuidador familiar desabafar, partilhar e aferir a gestão do quotidiano e sobretudo ser compreendido. Neste contexto, importa realçar o papel do enfermeiro especialista em saúde mental como coordenador do grupo. Este vê a família como parte integrante do processo de acompanhamento da pessoa doente, sendo o envolvimento da família como parceiro de cuidados desejável e aconselhável. As orientações às famílias são feitas com o desenvolvimento de intervenções que permitem a estimulação de aprendizagens e a transformação pessoal, na pessoa e sobre o outro. Assim no grupo são abordados vários temas como alternativas a desenvolver para lidar, saber gerir o impacto da doença mental no familiar doente e na família. De entre estes destacamos: informação sobre o quadro clínico e possibilidades de tratamento, sintomas, diagnóstico e prognóstico, a medicação e como lidar com episódios de crise, nomeadamente, estratégias mais adequadas e procedimentos necessários. É dada relevância ao trabalho das expetativas realistas. Salienta-se, ainda, a rede de apoio na família e na comunidade (Gomes et al., 2017).

Contudo, constatou-se que as orientações dadas às famílias no seio do grupo são de caráter pontual. E se ao doente é dado apoio e orientação antes e depois da alta o mesmo não acontece às famílias. A inexistência de programas estruturados com vista a preparar uma alta responsável e segura, cria 
dinâmicas de grande stresse no seio da família, sendo o grupo de suporte um recurso utilíssimo, mas de efeito escasso para a amplitude do problema de cuidar de uma pessoa com DMG em casa (Mcfarlane, 2016). Assim, importa mudar as conceções de cuidados à família ainda existentes, mais centrados na satisfação das necessidades do cliente e se avance para uma conceção de cuidados centrada no doente e família e no seu potencial de desenvolvimento. Nesta última conceção, acredita-se e reconhece-se que os laços de ligação familiar com - sistema de saúde geram forças que lhes permite desenvolver um papel de suporte e orientação na gestão de sintomas e na promoção do bemestar. Contudo, reconhece-se também os efeitos prejudiciais que pode ter no cuidador e família que podem entrar em sobrecarga se não forem devidamente acompanhados.

O facto da pessoa doente estar ausente neste grupo permite aos familiares a expressão de problemas que de outra forma poderiam ser reprimidos, embora esta opção possa ser vista como negativa pelas pessoas doentes por se sentirem excluídos e eventualmente ameaçados. A presença de outros familiares, tal como o estudo revelou e confirmado pela literatura, cria um ambiente de compreensão e as observações e comentários podem ser efetuadas de modo mais sincero e convincente do que aconteceria, se a interação fosse só realizada com profissionais (Fisher et al., 2015).

O apoio, suporte e orientação dos clientes nas transições de vida, em particular na transição de uma doença como é a DMG, são domínios de competência da prática dos cuidados de enfermagem. Importa olhar para a família que tem no seio um familiar com esta doença como um grande e imprescindível aliado e um parceiro de cuidados pois o seu projeto de vida e saúde encontra-se em inter-relação constante com o projeto de recuperação do familiar doente (Gomes, 2016).

\section{CONCLUSÕES}

Este estudo evidenciou que compreender a DMG como uma doença crónica, e não como um problema insolúvel e implacável, ou mesmo uma fatalidade, exige do cuidador familiar e família um longo caminho de aprendizagem. Esta necessidade deriva do peso do estigma que representa a doença mental ainda hoje presente na sociedade e vivido pela família, o que dificulta e limita o seu diálogo com familiares e amigos.

A existência de sistemas sociais mais amplos, como é - caso do grupo de suporte, pode ajudar a família a melhorar a comunicação entre si e entre familiares e amigos uma vez que a comunicação com a pessoa com DMG é uma área de elevada complexidade. A necessidade de verbalizar emoções negativas e receber suporte emocional é, efetivamente, facilitada pela dinâmica de liberdade e respeito encontrada no grupo de suporte. De facto, o espaço de liberdade e oportunidade na partilha de emoções e estratégias permite uma aprendizagem única no aceitar a DMG como uma doença crónica. O peso do estigma social que ainda perdura vai sendo lentamente esbatido.

grupo de suporte pela intensificação da partilha permite ao cuidador familiar libertar-se de estereótipos sociais. Possibilita ajuda aos familiares, passando a reaprendizagem por constatar diferentes maneiras de agir, motivar, ajudar, possibilitar, acreditar e aceitar. Aceitar o seu familiar doente como membro especial da sua família reconhecendo nele a fragilidade e dignidade, imanente em cada pessoa, é um caminho muito longo. A sociedade precisa libertar-se de preconceitos, no sentido de ver a pessoa com DMG como um ser humano completo. No sentido de aperfeiçoar a resposta ainda escassa às famílias das pessoas com DMG, parece importante promover a manutenção $e$ desenvolvimento destes grupos de suporte.

O funcionamento do grupo de suporte como este que aqui é referido pode servir de estímulo a que noutros contextos, onde o apoio às famílias é realizado de modo informal, se restruture e permita dinâmicas de trabalho que dêem visibilidade ao trabalho desenvolvido para ajudar as famílias. Todavia, no sentido da dinamização destes grupos, propomos melhorias no seu funcionamento com avaliações mais sistematizadas antes e após a intervenção planeada e consistente com as necessidades de orientação e apoio das famílias. 


\section{CONFLITOS DE INTERESSES}

Nenhum conflito financeiro, legal ou político envolvendo terceiros (governo, empresas e fundações privadas, etc.) foi declarado para nenhum aspecto do trabalho submetido (incluindo mas não limitandose a subvenções e financiamentos, conselho consultivo, desenho de estudo, preparação de manuscrito, análise estatística, etc).

\section{REFERÊNCIAS}

Crespo, J. (2006). Arte(s) de cuidar - Ciclo de colóquios. Loures: Lusociência.

Comissão Nacional para a Reestruturação dos Serviços de Saúde Mental. (2007). Relatório da proposta de plano de acção para a reestruturação e desenvolvimento dos serviços de saúde mental em Portugal 2007/2016. Lisboa: Autor. Recuperado de http://www.hmlemos. min-saude.pt/docs/PNacSM2007.pdf

De la Cuesta-Benjumea, Carmen. (2015). Aprender el oficio de investigar cualitativamente: formarse un self indagador. Rev Fac Nac Salud Pública, 33(supl 1): S22-S29. Recuperado de http://aprendeenlinea. udea.edu.co/revistas/index.php/fnsp/article/ view/24529. doi: 10.17533/udea.rfnsp.v33sla03

Figueiredo, M. H. J. S., \& Charepe, Z. B. (2010). Processos adaptativos da família à doença mental: os grupos de ajuda mútua como estratégia de intervenção. Rev Port Enferm de Saúde Mental, 3:24-30.

Fisher, E. B., Ayala, G. X., Ibarra, L., Cherrington, A. L., Elder, J. P., Tang, T. S., ... Simmons, D. (2015). Contributions of Peer Support to Health, Health Care, and Prevention: Papers from Peers for Progress. Ann Fam Med, 13 (suppl 1),S2-S8. Recuperado de http:// www.annfammed.org/content/13/Suppl_1/S2.full. pdf + html.

Gonçalves-Pereira, M., Wijngaarden, B., Xavier, M., Papoila, A. L., Caldas de Almeida, J. M., \& Shene, A. H. (2012). Caregiving in severe mental illness: the psychometric properties of the Involvement Evaluation Questionnaire in Portugal. Ann Gen Psychiatry, 1 1:8. Recuperado de https://www.ncbi.nlm.nih.gov/pmc/articles/ PMC3364850/. doi: 10.1186/1744-859X-11-8

Gomes, I. D. (2016). Promover o cuidado de si: parceria entre o enfermeiro e a pessoa idosa. A construção do processo de parceria num contexto de vulnerabilidade e dependência. Saarbrucken: Novas Edições Académicas.

Gomes, I. D., Lopes, M. A. P., Monteiro, M. C. P. D., Basto, M. L., Oliveira, C. S., Botelho, M. A. R., ... Henriques A. (2017). Grupo de Suporte à família da pessoa com doença mental grave: Um porto de abrigo na adversidade. Atas Congresso Ibero-Americano em Investigação Qualitativa, Salamanca, Espanha, 6.
Recuperado de: http://proceedings.ciaiq.org/index. php/ciaiq2017/article/view/1300

Grácio, J., Gonçalves-Pereira, M., \& Leff, J. (2015). What do we know about family interventions for psychosis at the process level? A systematic review. Family Process, 55(1), 79-90. Recuperado de http://onlinelibrary. wiley.com/doi/10.1111/famp.12155/full. doi: $10.1111 /$ famp.12155

Grácio, J., Gonçalves-Pereira, M., \& Leff, J. (2016). Key elements of a family intervention for schizophrenia: A qualitative analysis of a randomized controlled trial. Family Process, 1-13. Recuperado de http:// europepmc.org/abstract/med/27896805. doi: $10.1111 /$ famp. 12271

Kuipers, E., Leff, J., \& Lam, D. (2006). Family work for schizophrenia: A practical guide. (2nd ed). London: Gaskell Press.

Levy-Frank, I., Hasson-Ohayon, I., Kravetz, S., \& Roe, D. (2011). Family psychoeducation and therapeutic alliance focused interventions for parents of a daughter or son with a severe mental illness. Psychiatry Res, 189(2):173-179. Recuperado de https://www. ncbi.nlm.nih.gov/pubmed/21482437. doi: 10.1016/i. psychres.2011.02.012

Leininger, M. (2005). Criterios de evaluación y crítica de los estudios de investigación cualitativa. In Morse, J. M. (Ed.). Asuntos Críticos en los Métodos de Investigación Cualitativa, (pp. 137-170). Alicante: Universidade de Alicante.

McFarlane, W. R. (2016), Family Interventions for Schizophrenia and the Psychoses: A Review. Family Process, 55(3), 460-482. Recuperado de https://www. ncbi.nlm.nih.gov/pubmed/27411376. doi:10.1111/ famp. 12235

Meleis, A. I. (2010). Transitions theory. Middle range and situation specific Theories in nursing research and practice. New York: Springer and Publishing Company.

Nirmala, B. P., Vranda, M. N., \& Reddy, S. (2011). Expressed emotion and caregiver burden in patients with schizophrenia. Indian J Psychol Med, 33(2): 119. 122. Recuperado de https://www.ncbi.nlm.nih.gov/ pmc/articles/PMC3271 483/. doi: 10.4103/02537176.92052

Strauss, A., \& Corbin, J. (1998). Basics of qualitative research: techniques and procedures for developing grounded theory (2nd ed.). Thousand Oaks, California: Sage Publications.

Torres, S., Lima L., \& Guerra, M. (2014). Intervir em grupos na saúde ( $2^{a}$ ed.) Lisboa: Climepsi Editores. 